\title{
TEMPORAL POLE SIGNAL ABNORMALITY ON MR IMAGING IN TEMPORAL LOBE EPILEPSY WITH HIPPOCAMPAL SCLEROSIS
}

\section{A fluid-attenuated inversion-recovery study}

\author{
Henrique Carrete Junior ${ }^{1}$, Nitamar Abdala², Kátia Lin ${ }^{3}$, \\ Luís Otávio Caboclo ${ }^{3}$, Ricardo Silva Centeno ${ }^{3}$, Américo Ceiki Sakamoto4, \\ Jacob Szjenfeld ${ }^{5}$, Roberto Gomes Nogueira ${ }^{6}$, Elza Márcia Targas Yacubian ${ }^{7}$
}

\begin{abstract}
Objective: To determine the frequency and regional involvement of temporal pole signal abnormality (TPA) in patients with hippocampal sclerosis (HS) using fluid-attenuated inversion-recovery (FLAIR) MR imaging, and to correlate this feature with history. Method: Coronal FLAIR images of the temporal pole were assessed in 120 patients with $\mathrm{HS}$ and in 30 normal subjects, to evaluate gray-white matter demarcation. Results: Ninety (75\%) of 120 patients had associated TPA. The HS side made difference regarding the presence of TPA, with a left side prevalence ( $p=0.04, \chi^{2}$ test). The anteromedial zone of temporal pole was affected in $27(30 \%)$ out of 90 patients. In $63(70 \%)$ patients the lateral zone were also affected. Patients with TPA were younger at seizure onset $(p=0.018)$, but without association with duration of epilepsy. Conclusion: Our FLAIR study show temporal pole signal abnormality in $3 / 4$ of patients with $\mathrm{HS}$, mainly seen on the anteromedial region, with a larger prevalence when the left hippocampus was involved.
\end{abstract}

KEY WORDS: epilepsy, temporal lobe epilepsy, hippocampal sclerosis, temporal pole, magnetic resonance imaging.

\begin{abstract}
Anormalidade de sinal na imagem por RM do pólo temporal na epilepsia do lobo temporal com esclerose hipocampal: um estudo pela seqüência inversão recuperação com supressão da água livre (FLAIR)

RESUMO - Objetivo: Determinar a freqüência e o envolvimento regional da anormalidade de sinal do pólo temporal (APT) em pacientes com esclerose hipocampal (EH) utilizando seqüência inversão recuperação com supressão da água (FLAIR) por RM, e correlacioná-la com a história. Método: Foram analisadas as imagens coronais FLAIR dos pólos temporais de 120 pacientes com EH e de 30 indivíduos normais, para avaliar a demarcação entre substâncias branca e cinzenta. Resultados: Noventa (75\%) dos 120 pacientes tinham APT associada. Houve prevalência do lado esquerdo ( $p=0.04, \chi^{2}$ teste) na relação entre APT e o lado da EH. A zona ântero-medial estava acometida em 27 (30\%) destes pacientes. Em $63(70 \%)$ pacientes também a zona lateral estava acometida. Pacientes com APT apresentaram início da epilepsia quando mais jovens $(p=0.018)$, porém sem associação com a sua duração. Conclusão: A seqüência FLAIR mostra haver ATP em 3/4 dos pacientes com EH, principalmente na região ântero-medial, com maior prevalência quando o hipocampo esquerdo estava envolvido.
\end{abstract}

PALAVRAS-CHAVE: epilepsia, epilepsia do lobo temporal, esclerose hipocampal, pólo temporal, ressonância magnética.

\footnotetext{
${ }^{1}$ Mestre, Doutorando do Departamento de Diagnóstico por Imagem, Universidade Federal de São Paulo, Escola Paulista de Medicina, São Paulo SP, Brasil (UNIFESP-EPM); ${ }^{2}$ Doutor, Professor afiliado do Departamento de Diagnóstico por Imagem da UNIFESPEPM; ${ }^{3}$ Mestre, Doutorando do Departamento de Neurologia e Neurocirurgia da UNIFESP-EPM; ${ }^{4}$ Livre Docente, Professor afiliado Departamento de Neurologia e Neurocirurgia da UNIFESP-EPM; ${ }^{5}$ Livre Docente, Professor afiliado do Departamento de Diagnóstico por Imagem da UNIFESP-EPM; ${ }^{6}$ Doutor, Professor adjunto do Departamento de Diagnóstico por Imagem da UNIFESP-EPM; ${ }^{7}$ Doutor, Professor afiliado Departamento de Neurologia e Neurocirurgia da UNIFESP-EPM
}

Received 16 January 2007, received in final form 20 March 2007. Accepted 7 May 2007.

Dr. Roberto Gomes Nogueira - Rua Pará 126 / 52 - 01243-020 São Paulo SP - Brasil. 
Hippocampal sclerosis (HS) is the most frequent pathologic condition found in patients with refractory temporal lobe epilepsy (TLE) ${ }^{1,2}$. Ipsilateral temporal pole signal and volume abnormalities are described as part of the spectrum of MR imaging features found in cases of $\mathrm{HS}^{3-5}$. These abnormalities consist of loss of gray-white matter demarcation, with abnormal signal intensity predominantly in white matter, seen on T2-weighted images, and ipsilateral temporal lobe atrophy.

The clinical significance and underlying histopathology of these temporopolar abnormalities have not been conclusively established ${ }^{3-6}$. It is not known whether this signal abnormality represent damage from chronic epilepsy or early injury, however the occurrence of this change in pediatric cases of HS with a similar prevalence suggests that it is not an acquired abnormality?

Our aim was to study a large series of patients with $\mathrm{HS}$ to examine the prevalence and clinical correlations of temporal pole signal abnormality (TPA) using fluid-attenuated inversion-recovery (FLAIR) MR images. We also attempted to determine the value of this MR imaging feature for the presurgical lateralization of epileptic focus and if there is any hemisphere prevalence.

\section{METHOD}

Patients and control subjects - We studied 120 patients with medically intractable TLE and MR findings of unequivocal HS, represented by visual hippocampal atrophy and FLAIR/T2 hypersignal on coronal images (53 males, mean age $35.9 \pm S D=9.7$ years, range $=15$ to 62 ). They belong to $a$ consecutive series of patients who had undergone evaluation for epilepsy surgery for TLE between 2003 and 2005. Patients were excluded if the MRI showed other diseases such as tumor, developmental, vascular or other destructive lesion in the anterior temporal region. Patients with extra-axial lesion, such as arachnoid cyst, in the medial cranial fossa or with motion or any other type of artifact in the temporal pole were also excluded. The epileptogenic temporal lobe was identified by prolonged EEG and/or videoEEG monitoring (72 patients) and neuropsychological assessments performed in all patients. Fifty-one patients had surgery and qualitative histopathological examination confirmed HS. Sixty-nine patients await or refused surgery.

The MR control population consisted of 30 neurologically normal controls ( 14 males, mean age $33 \pm S D=8.8$ years, range $=22$ to 58 ). All volunteers were free of neurologic or psychiatric symptoms and were not taking any medications.

Patients and normal control subjects did not differ in age ( $t$ test; $t_{148}=-15.2, p=0.131$ ), handedness (Fisher test; $p>0.999$ ) or gender distribution (Chi Square Test $; \chi^{2}=0.061$, $\mathrm{df}=1, \mathrm{p}=0.805$ ).

This study was approved by the Ethics Committee for Human Research at Federal University of São Paulo. All studies were done following informed consent.

Clinical and EEG details - Seizure types and the site of seizure onset were determined by a comprehensive evaluation including detailed history, neurological examination, interictal scalp EEG and/or prolonged EEG-video monitoring, and neuropsychological evaluation. The mean age at the onset of epilepsy was $15 \pm 10$ years (range, 0.6 to 55 ). At the time of imaging, the mean duration of epilepsy (age at MRI minus age of epilepsy onset) was $25 \pm 11$ years (range, 1 to 56). Ninety-seven out of 120 patients presented simple partial seizures (SPS), with a monthly median frequency of 4 (0.16 to 30$)$. All 120 patients had complex partial seizures

Table 1. Demographic and clinical characteristics of temporal lobe epilepsy patients $(n=120)$.

\begin{tabular}{lccc}
\hline Clinical characteristics & Mean & \pm SD & Range \\
\hline Age at MRI, yrs & 35.9 & 9.7 & $15-62$ \\
Age at onset, yrs & 15 & 10 & $0.6-55$ \\
Duration of epilepsy, yrs & 25 & 11 & $1-56$ \\
Age at IPI, yrs & 1.81 & 1.56 & $0.08-8$ \\
FS+, n (\%) & $38(31.6 \%)$ & & \\
\hline
\end{tabular}

SD, standard deviation; FS+, history of febrile seizures in childhood.

Table 2. Type and monthly median frequency of seizures of temporal lobe epilepsy patients $(n=120)$.

\begin{tabular}{lccc}
\hline Type of seizures & $\mathrm{n}(\%)$ & Median & Range \\
\hline Simple partial seizures & $97(81)$ & 4 & $0.16-30$ \\
Complex partial seizures & $120(100)$ & 4 & $0.16-60$ \\
GTC+ & $64(53.3)$ & 1.5 & $0.50-30$ \\
\hline
\end{tabular}

GTC+, at least six secondary generalized seizures/year. 


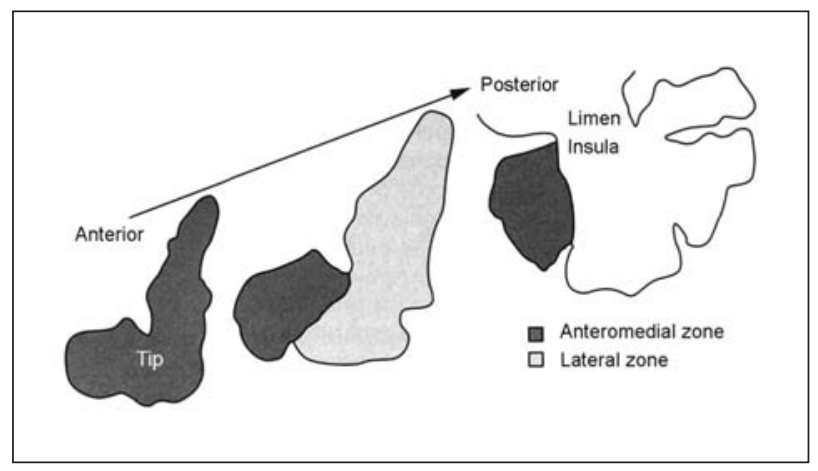

Fig 1. Schematic drawing of left temporal pole, from anterior to posterior, showing the two distinct zones, used for classification of TPA topography.

(CPS), also 4 a month (0.16 to 60). Sixty-four patients had secondary generalized seizures occurring at least 6 times per year $(\mathrm{GTC}+$ ), whereas 56 reported only rare (fewer than 6 per year) or no secondary generalization (GTC -). The monthly median frequency of seizures in GTC + patients was 1.5 (0.5 to 30).

Febrile seizures (FS) in childhood were observed in 38 out of 120 patients $(31.6 \%)$. Ten had history of other "initial precipitating incidents (IPI)" (8.3\%). The mean age at FS occurrence or other IPI was $1.81 \pm 1.56$ years (range, 0.08 8 ). Demographic and clinical characteristics of the patient population are summarized in Tables 1 and 2 .

MR image acquisition - Patients and control subjects underwent imaging with a 1.5-T Gyroscan (Philips Medical System, Eindhoven, The Netherlands) using a standard head coil. The protocol included the following: sagittal T1-weighted (repetition time $[T R]=433$ milliseconds, echo time $[T E]=13$ milliseconds, field of view $(F O V)=25 \mathrm{~cm}$, $6 \mathrm{~mm}$ slice thickness, matrix size $=256 \times 512$ ); axial turbospin echo T2-weighted ( $T R=4535$ milliseconds, $T E=100$ milliseconds, $\mathrm{FOV}=23 \mathrm{~cm}, 6 \mathrm{~mm}$ slice thickness, matrix size $=256$ $x$ 512); axial gradient-echo T2*-weighted (TR=707 milliseconds, TE $=23$ milliseconds, flip angle of $15^{\circ}, F O V=23 \mathrm{~cm}$, $6 \mathrm{~mm}$ slice thickness, matrix size $=205 \times 256)$; inversion recovery (IR) T1-weighted ( $T R=5620$ milliseconds, $T E=17$ milliseconds, inversion time $[\mathrm{TI}]=400$ milliseconds) and fluid attenuated inversion recovery (FLAIR) ( $T R=8000$ milliseconds, $\mathrm{TE}=150$ milliseconds, $\mathrm{Tl}=2350$ milliseconds) with the same section thickness, FOV and matrix ( $3 \mathrm{~mm}, 23 \mathrm{~cm}, 256$ x 512) in the coronal planes perpendicular to the long axis of hippocampus, including the totality of the temporal lobe; fast field echo (FFE) T1-weighted ( $T R=30$ milliseconds, TE=4.6 milliseconds, one acquisition average pulse sequence, flip angle $=45^{\circ}, F O V=23 \mathrm{~cm}, 1.5 \mathrm{~mm}$ slice thickness with no gaps, matrix size $=228 \times 512$, in the coronal plane. The control group underwent only the coronal FLAIR and FFE T1weighted sequences.

MR qualitative analysis - First four slices that included the temporal poles obtained by coronal FLAIR images from both groups (patients and controls) were mixed to- gether and sent to a workstation. Two experienced observers independently assessed the images for TPA. The criteria for an abnormal case included increased signal in the white matter and loss of gray-white matter demarcation of the temporal pole. In a second step the positive cases were evaluated for the topography of the TPA. Two different zones were distinguished: anteromedial and lateral temporal pole. This distinction was made by Ostrowsky et al. ${ }^{8}$ performing intracortical electrical stimulations of temporopolar cortex and is based on the findings of Insausti et al. ${ }^{9}$ who used a series of coronal MRI slices to map the borders of temporo-polar cortex (Fig 1). Temporal pole size was not considered in this analysis. The observers were aware that the patients had TLE and HS on MR but were unaware of the lateralizing data and if they were evaluating a patient or a control subject. Cohen's Kappa score was used to evaluate the inter-rater agreement for the detection of TPA. A [Kappa] score of $>0.60$ was considered to indicate substantial to excellent agreement. When there was a discrepancy about the results, a final consensus was obtained by reviewing the discordant cases.

Statistical analysis - All contingency data were summarized as number (\%) or by means \pm standard deviation according to the type of variable. The proportion and respectively $95 \%$ confident interval $(95 \% \mathrm{Cl})$ were calculated for TPA. Numeric variables were compared using Student's $t$ tests. Categorical variables were compared using chi square or Fisher's exact tests. The significance level was set as $p<0.05$.

\section{RESULTS}

One hundred and seven out of 120 patients (89\%) had unilateral HS (38\% right, 51\% left) and 13 patients $(11 \%)$ had bilateral. The control images of 30 volunteers showed no signal of HS or other significant abnormalities.

The inter-rater agreement was excellent for detecting an abnormal increased signal in the white matter and loss of gray-white matter demarcation of the temporal pole in coronal FLAIR images (Cohen's Kappa score 0.93).

Ninety (75\%) of the 120 patients (95\% Cl [66.3\%; $82.5 \%]$ ) with HS had TPA on coronal FLAIR images. TPA was found in 10 out of 13 cases presenting bilateral HS (4 on the right and 6 on the left temporal pole). In 7 out of 10 patients with bilateral HS and findings of TPA, the abnormalities were ipsilateral to the more affected hippocampus (Fig 2). In 80 patients presenting unilateral HS with TPA, the abnormalities were ipsilateral in 79 (26 right TP, 53 left). In the remaining patient, who had right HS, we found bilateral TPA.

The side of the HS made a difference regarding the presence of TPA, being more frequent on the left side involvement ( $p=0.04, \chi^{2}$ test; Table 3$)$. Excluding bilateral cases of HS, the difference was even more 


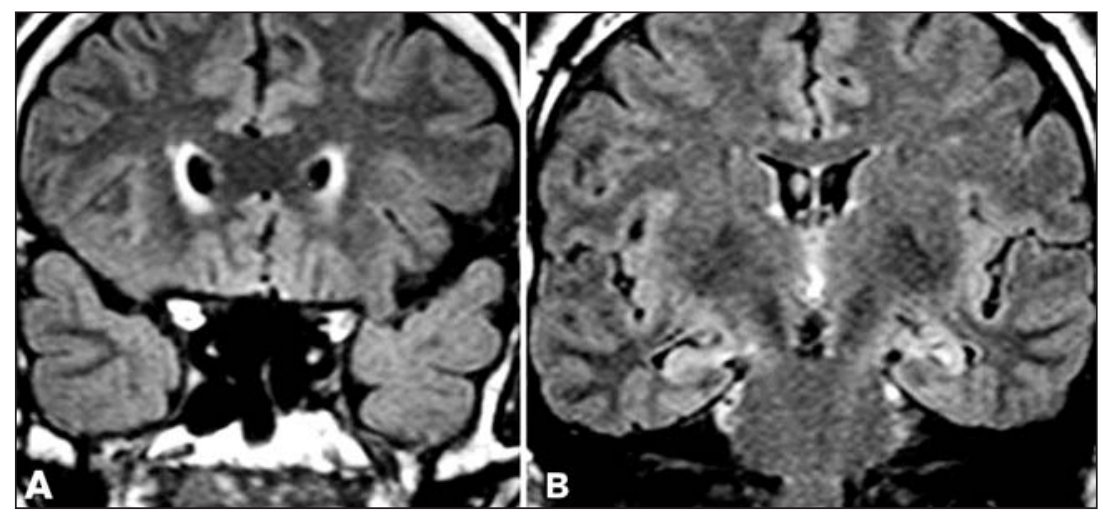

Fig 2. Patient with bilateral HS. Coronal FLAIR images at the level of temporal pole (A) and hippocampus (B). (A) Left temporal pole loss of gray-white matter demarcation, with abnormal signal intensity predominantly in white matter. Signal abnormality is on the anteromedial and lateral zone of left temporal pole. Right temporal pole is normal. (B) Bilateral hippocampal increased signal intensity, more severe on the left side, ipsilateral to TPA.
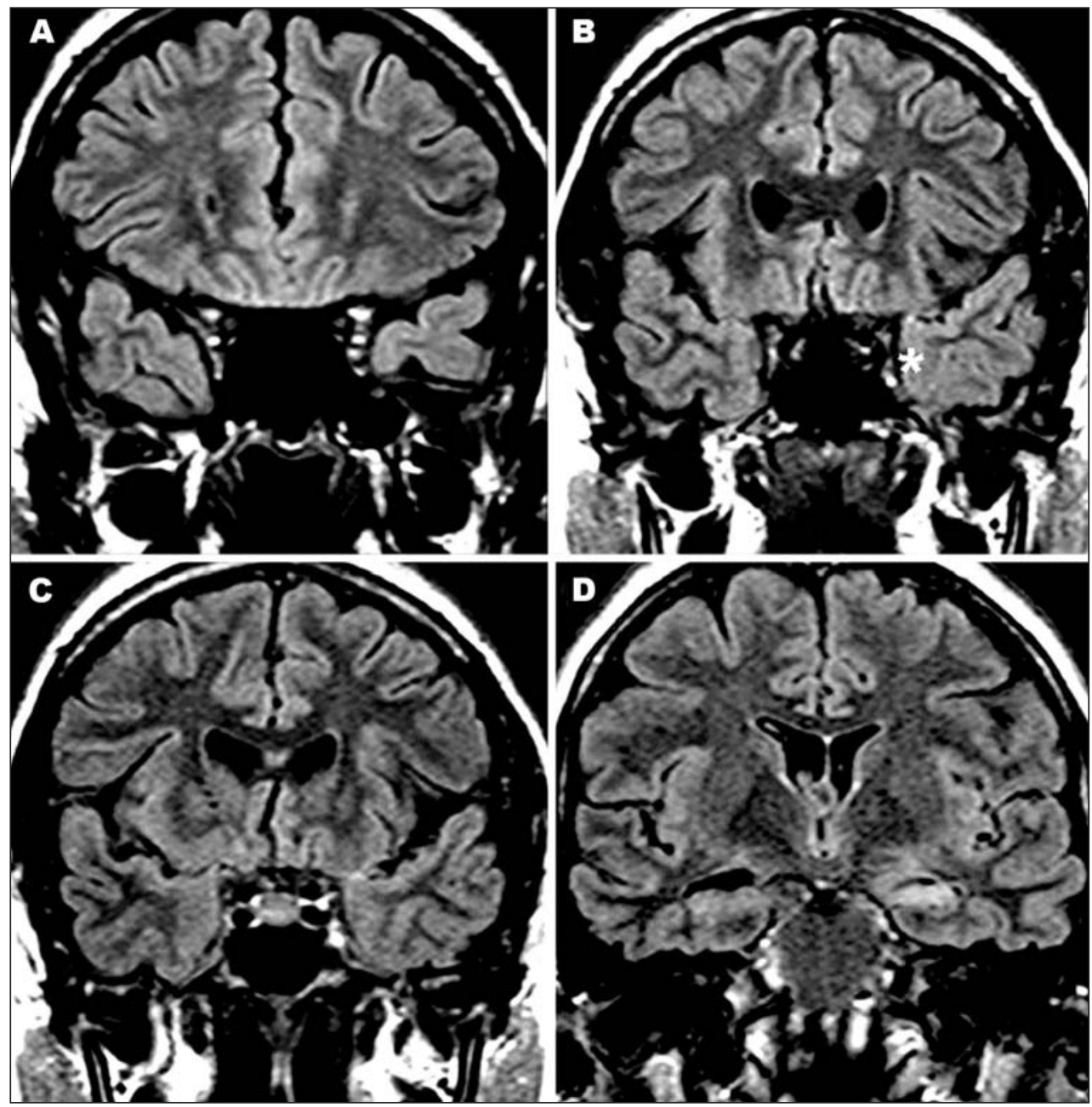

Fig 3. Images of a patient wiht left HS and ipsilateral TPA. Coronal FLAIR images at the level of temporal pole (A to $C$ ) and of the hippocampal head (D). It is possible to note that the abnormality is recognized at the tip (A) and anteromedial zone (asterisk) (B) of left temporal pole. The following slice shows no signal abnormality (C). Typical left hippocampal sclerosis, with increased signal intensity (D). 
Table 3. Frequency of temporal pole signal abnormalities (TPA) in patients with hippocampal sclerosis.

\begin{tabular}{lcccc}
\hline TPA & \multicolumn{3}{c}{ Hippocampal sclerosis } & \multirow{2}{*}{ Total } \\
\cline { 2 - 4 } & Right & Left & Bilateral & \\
\hline Present & $27(30 \%)$ & $53(59 \%)$ & $10(11 \%)$ & 90 \\
Absent & $19(63 \%)$ & $8(27 \%)$ & $3(10 \%)$ & 30 \\
\hline
\end{tabular}

chi-square test: $p=0.04$

significant $(p=0.001)$. There were no cases with TPA contralateral to HS. The control images of $30 \mathrm{vol}-$ unteers showed no signal abnormalities in temporal poles.

According to the topography of the abnormality in the 90 patients with TPA on coronal FLAIR images, $27(30 \%)$ had the anteromedial zone affected. The other $63(70 \%)$ patients had both lateral and anteromedial zones affected. In none of the 90 patients with TPA the affected zone was isolated on the lateral part of the temporal pole.

We found no gender differences between patients with and without TPA ( $p=0.243)$. Also, there were no statistical differences according to history of FS in childhood and other IPI ( $p=0.821 ; p=0.448)$. According to the age at occurrence of FS or other IPI, we found that patients with TPA were, in average, $1.1 \pm 0.5$ years younger than those without it, with a marginally statistically significance $(p=0.053)$. According to the age at seizure onset, patients with TPA were younger and had their CPS and CPC, in average, $5.9 \pm 2.2$ and $5.0 \pm 2.1$ years before those with- out it ( $p=0.009$ and $p=0.018$, respectively). There was no statistic difference in the duration of epilepsy $(p=0.440)$ or seizure frequency between patients with and without TPA (CPS, $p=0.104 ; C P C, p=0.133$; GTCS, $p=0.616$ ). The main clinical results are resumed in Table 4.

Forty-six out of 51 patients submitted to temporal lobectomy had video-EEG demonstrating the origin of seizures ipsilateral to HS, with thirty-five $(76 \%)$ of them presenting TPA. Other 11 had concordant videoEEG and HS lateralization, but normal temporal pole on FLAIR images. Four patients had bilateral seizures origin during continuous video-EEG monitoring and in three of whom with TPA ipsilateral to HS. In the other patient, HS was bilateral on MRI but with TPA ipsilateral to the more affected hippocampus (Fig 3).

The mean time of post-surgical follow-up was 38.2 months. Temporal pole signal abnormalities were not associated with the postoperative seizure outcome.

\section{DISCUSSION}

In the present study of medial TLE, temporal pole signal abnormalities were found in three quarter of patients with HS detected by high resolution MRI. This is higher than usually reported in the literature where TPA with an increased T2-weighted signal in the white matter, resulting in a loss of gray-white matter definition, has been found in $32 \%$ to $71 \%$ on MR images of patients with $\mathrm{TLE}^{3-7}$. We preferred to examine the temporal pole with coronal FLAIR images and this may partially explain better results

Table 4. Clinical features according to temporal pole signal abnormalities (TPA) in patients with hippocampal sclerosis.

\begin{tabular}{|c|c|c|c|}
\hline \multirow[t]{2}{*}{ Clinical features } & \multicolumn{2}{|c|}{ TPA } & \multirow[t]{2}{*}{$\mathrm{p}$-value } \\
\hline & Present $n=90$ & Absent $n=30$ & \\
\hline Gender & & & 0.243 \\
\hline Male & $37(41.1 \%)$ & $16(53.3 \%)$ & \\
\hline Female & $53(58.9 \%)$ & $14(46.7 \%)$ & \\
\hline Febrile seizures & & & 0.821 \\
\hline Yes & $29(32.2 \%)$ & $9(30.0 \%)$ & \\
\hline No & $61(67.8 \%)$ & $21(70.0 \%)$ & \\
\hline Other IPI & & & 0.448 \\
\hline Yes & $9(10.0 \%)$ & $1(3.3 \%)$ & \\
\hline No & $81(90.0 \%)$ & $29(96.7 \%)$ & \\
\hline Age in years at $\mid \mathrm{PI}^{\#}$ & $1.6 \pm 1.3$ & $2.7 \pm 2.1$ & 0.053 \\
\hline \multicolumn{4}{|c|}{ Age in years of onset of epilepsy } \\
\hline Simple partial seizures $\# \#$ & $12.8 \pm 8.7$ & $18.7 \pm 10.5$ & 0.009 \\
\hline Complex partial seizures & $13.4 \pm 8.9$ & $18.4 \pm 12.2$ & 0.018 \\
\hline Epilepsy duration in years & $21.7 \pm 10.9$ & $20.0 \pm 8.6$ & 0.440 \\
\hline
\end{tabular}

"present, $n=38$; absent, $n=10$; "\#present, $n=75$; absent, $n=22$. 
for that finding, in contrast to others authors who used spin-echo or fast spin-echo T2 sequences. Interesting to note is the fact that the nearest result to ours $(71 \%$ vs $75 \%)$ is that reported by Meiners et al. ${ }^{3}$, detecting TPA in T2-weighted images parallel to the long axes of the hippocampi, but in a small series of 14 patients. Fluid-attenuated inversionrecovery MR imaging provides heavy $\mathrm{T} 2$-weighting without cerebrospinal fluid-related artifacts or volume-averaging effects. This technique has assumed an important role in routine brain imaging and it is recommended in MR evaluation of patients with epilepsy because of its presumed ability to enhance the visibility of brain lesions compared with that of proton density-weighted and of T2-weighted spin-echo sequences ${ }^{10-12}$. The use of FLAIR sequences increases detection accuracy not only for periventricular but also for cortical-subcortical lesions as is the case for TP region. Our study design did not assess the effects of varying the window width and level, but the examiners using this tool were more confident to decide for the presence of TP sign abnormalities. In previous studies, MR images have shown that TPA is not present in normal individuals ${ }^{4,7,13}$. In agreement with these results, there were no TP signal abnormalities in the 30 normal subjects.

Our results indicate that TPA occurs ipsilateral to HS in the unilateral cases, also similar to previous studies $^{3,5-7}$. The incidence of TPA, including purely our bilateral cases of HS, was $77 \%$ (10 out of 13 patients), similar to overall cases (uni plus bilateral). Furthermore, in $70 \%$ of these positive cases for TPA with bilateral $\mathrm{HS}$, the abnormalities were ipsilateral to the more affected hippocampus on MRI (more atrophic and/or bright on T2). This finding in bilateral HS is similar to that reported by Mitchell et al. ${ }^{7}$ who reported a case of TPA only on the side of the most severe hippocampal atrophy in one out of two cases of bilateral HS, in a series of 54 children with typical HS investigated by MRI. Before that, Choi et al. ${ }^{6}$ reported the presence of TPA in two patients with bilateral HS only in the temporal lobe that had been determined as the epileptogenic zone on EEG. We believe that the finding of unilateral TPA on MRI may contribute in the pre-surgical evaluation of patients with bilateral HS.

In our series, the majority of operated patients had concordant lateralization according to video-EEG monitoring and HS detected by MRI (90\%). Nevertheless, in three TLE patients who were candidates for surgical treatment, non-invasive video-EEG did not contribute for lateralization of the epileptogenic temporal lobe, whereas TPA was present and ipsilateral to HS in all. According to surface ictal EEG patterns, a recent study from our group with a subset of patients from theses series, showed no correlation with temporal pole signal abnormalities, suggesting that even whether these findings might be helpful in lateralizing the epileptogenic zone, the temporal poles could not be crucially involved in the process of epileptogenesis ${ }^{14}$.

Other interesting finding in our series was that in unilateral cases of HS the incidence of TPA was higher when the affected hippocampus was on the left side ( $87 \%$ vs $59 \%)$. This finding contrasts with previous studies showing that the side of HS made no difference regarding the presence of TPA ${ }^{4,7}$. Little is understood about the genetic or epigenetic mechanisms that underlie brain asymmetry or asymmetric brain involvement. Some reports have suggested that the left cerebral hemisphere is more susceptible to cortical damage ${ }^{15,16}$. Chiron et al. ${ }^{17}$ have shown that the development of functional brain asymmetry during childhood was confirmed by changes in the cerebral blood flow measured at rest with dynamic single photon emission computed tomography. Between 1 and 3 years of age, the blood flow shows a right hemispheric predominance. Due to the high blood flow in the right cerebral hemisphere, the left hemisphere may be more sensitive for cerebrovascular insult, especially in infants ${ }^{18}$. Additionally, this period is coincident with the occurrence of the IPI. Retrospective studies from surgical series have demonstrated a high incidence of IPI in patients with MTLE with $\mathrm{HS}^{19}$. In temporal lobe epilepsy, Taylor ${ }^{20}$ showed a transient left hemisphere vulnerability in early life and suggested this reflected a difference of development pace.

Few studies discuss differences in structural involvement of the brain between patients with left and right medial TLE. Usually, patients with left medial TLE show more areas of gray matter reduction compared with controls, than those with right medial TLE ${ }^{21,22}$. Bonilha et al. ${ }^{23}$ in a recent study, using voxel-based morphometry analyses of MRI, showed that patients with left medial TLE exhibit more intense and widespread neuronal damage than those with right medial TLE. The authors suggested as possible explanation for these findings a more excitotoxic damage when seizures were originating in the dominant hemisphere.

These differential rates of side involvement may contribute to explain differences in the incidence of 
TPA in patients with medial TLE in other series. In Mitchell et al. ${ }^{7}$ pediatric series of patients with unilateral HS (26 right, 25 left), 57\% of the patients had anterior temporal changes. We speculate if the incidence would be larger if they had more patients with left HS, as in our series.

We classified the TPA according to its extension in medial and lateral. We believe that making a distinction between these two different zones could be interesting since the temporal pole cortex is composed of different zones according to cytoarchitectonic structure. The anteromedial temporal pole cortex corresponds to the agranular and dysgranular non-isocortical tissue and the lateral temporal polar cortex (other than the lateral part of its tip) corresponding to the granular isocortical tissue ${ }^{8}$. In 27 out of 90 (30\%) patients with TPA, the abnormalities were identified in the medial region alone. Other 63 patients $(70 \%)$ had their signal abnormalities in FLAIR images affecting lateral and medial regions. In none of the 90 patients TPA could be found in lateral region alone. These findings could further contribute to explain differences in incidence of TPA in different series ${ }^{3-7}$. If more anterior slices of temporal pole were excluded from the analysis, then we could have had a lower incidence of these findings (63 patients out of $120,52.5 \%$ ) (Fig 3). It appears that paralimbic damage associated with HS more often affects the structures most closely connected to the hippocampus. In a general sense, there seems to be a correspondence between the cytoarchitectonic nature of the temporal pole subsector and the type of projections that it receives. The more differentiated granular part of TP receives a larger proportion of its afferents from parts of cortex that also have isocortical architecture. In contrast, the less-differentiated dysgranular and agranular-periallocortical areas receive a larger proportion of their afferents from nonisocortical paralimbic regions and from limbic structures ${ }^{24}$. We remember that the TP agranularperiallocortical sector covers part of the free medial surface of the temporal pole and extends caudally beyond the limen insula until the emergence of the amygdala. This zone was affected in all cases where TPA were present, some cases without signal abnormalities in the lateral zone (30\%). Therefore it's imperative to study this region more thoroughly in mesial TLE patients.

According to gender (male vs female), handedness, and mean age at time of MR imaging there were no statistically significant differences between patients with and without TPA. In agreement with our results, Mitchell et al. ${ }^{7}$ found no differences according to gender and age in their series studying TPA in children with HS. It is important to notice the fact that in their study they showed TPA in pediatric cases of HS similar to that seen in adult cases. Our experience with HS in children is similar although not shown in this study.

We found that TPA is not associated with a history of IPI. Other studies with smaller series showed a more prevalent history of $\mathrm{FS}^{6}$ or even statistically significant ${ }^{5}$ in patients with TPA and HS when compared to patients without them. Similar association has not been found by Mitchell et al. ${ }^{7}$ more recently, who, in accordance with our results, were history details would be more confident because the authors examined a pediatric group of HS. But regarding to the age of patients, they were younger at the time of IPI when presenting TPA than patients without TPA, a similar finding for our series. Patients with TPA were also younger at the onset of epilepsy, independently if it was of simple or complex type. Nevertheless, we did not find a correlation between TPA and duration of epilepsy ( $p=0.44)$, in agreement with the series of Choi et al. ${ }^{6}$, and seizure frequency. These findings may support the hypothesis that cumulative damage from repeated seizures in the course of chronic temporal lobe epilepsy do not causes TPA. Therefore, we agree with the statement of Mitchell et al. ${ }^{7}$ that if seizures are the cause, TPA probably develops at or soon after the onset of seizures.

To conclude, the current study findings highlight the importance of MRI-temporal pole abnormality in TLE patients with HS, which is significantly more frequent when the left hemisphere is affected. Our data indicate that temporal pole abnormalities are always ipsilateral to unilateral HS and usually ipsilateral to the more affected hippocampus in bilateral cases, and may suggest widespread abnormality affecting the temporal lobe. We demonstrated that the lateral part of temporal pole is not involved in all cases of signal abnormality on FLAIR images, and these contrasted with the anteromedial part which was consistently affected, and this finding may be related to the cytoarchitectonic nature of the temporal pole. Temporal pole signal abnormality was associated with early onset of epilepsy and early IPI. The left side predominance of damage may be related to the occurrence of cerebral insult during a period of life where the blood flow shows a right hemispheric predominance, which is coincident with the age of majority of the IPI, or be a consequence of side sensitivity to seizures. 


\section{REFERENCES}

1. Falconer MA, Serafetinides EA, Corsellis JAN. Etiology and pathogenesis of temporal lobe epilepsy. Arch Neurol 1964;10:233-248.

2. Babb TL, Brown WJ. Pathological findings in epilepsy. In: Engel J Jr, editor. Surgical treatment of the epilepsies. New York: Raven Press, 1987: 511-540.

3. Meiners LC, Gils A, Jansen GH, et al. Temporal lobe epilepsy: the various MR appeareances of histologically proven mesial temporal sclerosis. Am J Neuroradiol 1994;15;1547-1555.

4. Meiners LC, Witkamp TD, de Kort GAP, et al. Relevance of temporal lobe white matter changes in hippocampal sclerosis: magnetic resonance imaging and histology. Invest Radiol 1999;34:38-45.

5. Mitchell LA, Jackson GD, Kalvins RM, et al. Anterior temporal abnormality in temporal lobe epilepsy: a quantitative MRI and histopathologic study. Neurology 1999;52:327-336.

6. Choi D, Na DG, Byun HS, et al. White matter change in mesial temporal sclerosis: correlation of MRI with PET, pathology, and clinical features. Epilepsia 1999;40:1634-1641.

7. Mitchell LA, Harvey AS, Coleman LT, Mandelstam SA, Jackson GD. Anterior temporal changes on MR images of children with hippocampal sclerosis: an effect of seizures on the immature brain? Am J Neuroradiol 2003;24:1670-1677.

8. Ostrowsky K, Desestret V, Ryvlin P, Coste S, Mauguière F. Direct electrical stimulations of the temporal pole in human. Epileptic Disord 2002;4(Suppl 1):S23-S27.

9. Insausti R, Juottonen $K$, Soininen $H$, et al. MR volumetric analysis of human entorhinal, perirhinal, and temporo-polar cortices. Am J Neuroradiol 1998;19:659-671.

10. Jack CR Jr, Rydberg CH, Krecke KN, et al. Mesial temporal sclerosis: diagnosis with fluid-attenuated inversion-recovery versus spin-echo MR imaging. Radiology 1996;199:367-373.

11. Meiners LC, van Gils AD, De Kort G, van der Graaf Y, Jansen GH, van Veelen CW. Fast fluid-attenuated inversion recovery (FLAIR) compared with T2-weighted spin-echo in the magnetic resonance diagnosis of mesial temporal sclerosis. Invest Radiol 1999;34:134-142.

12. Herskovits E, Itoh R, Melhem ER. Accuracy for detection of simulated lesions: comparison of fluid-attenuated inversion-recovery, proton density-weighted, and T2-weighted synthetic brain MR imaging. Am J Roentgenol 2001;176:1313-1318.

13. Coste S, Ryvlin P, Hermier M, et al. Temporopolar changes in termporal lobe epilepsy: a quantitative MRI-based study. Neurology 2002;59: 855-861.

14. Caboclo LOSF, Garzon E, Oliveira PAL, et al. Correlation between temporal pole MRI abnormalities and surface ictal EEG patterns in patients with unilateral mesial temporal lobe epilepsy. Seizure 2007;16:8-16.

15. Parker CE, Harris N, Mavalwala J. Dyke-Davidoff-Masson syndrome. Five cases studies and deductions from dermatoglyphics. Clin Pediatr 1972;11:288-292.

16. Dean AC, Solomon G, Harden C, Papakostas G, Labar DR. Left hemispheric dominance of epileptiform discharges. Epilepsia 1997;38: 503-505.

17. Chiron C, Lambaque I, Nabbout R, Lounes R, Syrota A, Dulac O. The right brain hemisphere is dominant in human infants. Brain 1997;120:1057-1065.

18. Ünal Ö, Tombul T, Grak B, Anlar Ö, Incesu L, Kayan M. Left hemisphere and male sex dominance of cerebral hemiatrophy (Dyke-Davidoff-Masson syndrome). Clin Imaging 2004;28:163-165.

19. Wieser HG for the ILAE Commission on Neurosurgery of Epilepsy. ILAE Comission Report: mesial temporal lobe epilepsy with hippocampal sclerosis. Epilepsia 2004;45:695-714.

20. Taylor DC. Differential rates of cerebral maturation between sexes and between hemispheres. Evidence from epilepsy. Lancet 1969;2:140-142.

21. Bernasconi N, Duchesne S, Janke A, Lerch J, Collins DL, Bernasconi A. Whole-brain voxel-based statistical analysis of gray matter and white matter in termporal lobe epilepsy. Neuroimage 2004;23:717-723.

22. Bonilha L, Rorden C, Castellano G, Pereira F, Rio PA, Cendes F, Li LM. Voxel-based morphometry reveals gray matter network atrophy in refractory medial temporal lobe epilepsy. Arch Neurol 2004;61:13791384.

23. Bonilha L, Rorden C, Halford JJ, et al. Asymmetrical extra-hippocampal grey matter loss related to hippocampal atrhophy in patients with medial temporal lobe epilepsy. J Neurol Neurosurg Psychiatry 2007;78: 286-294.

24. Morán MA, Mufson EJ, Mesulan MM. Neuronal inputs into the temporopolar cortex of the rhesus monkey. J Comp Neurol 1987;256:88-103. 